\title{
GYNECOLOGICAL/OBSTETRIC BACKGROUND AND RHEUMATOID ARTHRITIS: A CROSS SECTIONAL STUDY IN BRAZILIAN PATIENTS
}

\author{
Anauá Fernanda dos Santos Cavalcante ${ }^{1, \star}$, Patrícia Martin ${ }^{1}$, Thelma Larocca Skare ${ }^{1}$ \\ 1.Hospital Universitário Evangélico Mackenzie, Curitiba (PR), Brazil. \\ ${ }^{\star}$ Corresponding author: anaua.cavalcante@hotmail.com
}

\section{BACKGROUND}

Rheumatoid arthritis (RA) and female reproduction have been linked in the literature for decades. Gynecological and obstetrical history has been studied in this context. Herein, we studied a sample of RA for their gynecological/obstetric history comparing them with controls, aiming to know their influences of number of pregnancies, menarche, menopause and reproductive years in RA onset in the occurrence of the disease in our region.

\section{MATERIALS AND METHODS}

This is a cross-sectional study of 122 RA patients and 126 controls. Patients and controls were questioned about age of menarche, age of menopause, number of pregnancies and abortions. Reproductive years were calculated as the difference between age at menopause and age at menarche. Charts of RA patients were reviewed for clinical and serological data. Control females were from the hospital employees and their relatives. For comparison, we used Mann-Whitney, unpaired t testes, chi-squared test and Spearman test. The adopted significance was $5 \%$.

\section{RESULTS}

In the RA patients with disease beginning at post menopause, the period of reproductive years (age at menopause - age of menarche) showed a positive correlation with age at disease onset ( $r h o=0.46 ; 95 \% \mathrm{Cl}=0.20-0.55$ with $p=0.0008$ ). When the age of menopause of controls was compared with the age of menopause in RA patients with disease onset after menopause, we found that in controls the median age of menopause was 50 years (IQR $=47.0-51.5)$ while it was 46.0 (IQR $=42.7-50.0)$ in $R A$ patients, with $p=0.003$. The number of pregnancies was higher in patients with disease onset at post-menopause when compared with those with premenopausal (median of 3 with IQR $=2-4$ versus median of 2 with IQR $=1-3 ; p=0.009$ ) and RA patients had more pregnancies than controls $(p=0.0002)$.

\section{CONCLUSIONS}

Rheumatoid arthritis patients have earlier menopause and late menarche than controls, suggesting that the reproductive years in RA females are diminished and that RA onset at post menopause patients and controls have more pregnancies. Concluding, the present study shows that, in our population, the decrease in reproductive years and the high number of pregnancies are linked to RA appearance. 